\title{
Performance Evaluation of Self-Excited Cage And Cageless Three Phase Synchronous Reluctance Generator
}

\author{
A. O. Ojo ${ }^{1}$, F. I. Izuegbunam ${ }^{2}$, M. Olubiwe ${ }^{3}$ \\ ${ }^{1,2,3}$ Department of Electrical and Electronic Engineering, Federal University of Technology, Owerri, Nigeria.
}

\begin{abstract}
The concept of generating electrical power using reluctance generator is yet to be fully exploited, which will necessitate its development into industrial standard. This research aims to facilitate the development through a comparative evaluation of the performance of caged and cageless reluctance generators. A three-phase synchronous reluctance generator was modeled using existing information and its performance with or without a cage rotor was analyzed. Evaluation of the machines' performance was carried out at both steady and dynamic states using MATLAB. The results show that a self-excited cage rotor synchronous reluctance generator yielded a power of 0.25 p.u compared to the cage-less rotor that yielded 0.2 p.u at an excitation of $62 \mu \mathrm{F}$; while on further excitation using capacitance of $110 \mu \mathrm{F}$, the cage rotor yielded a higher power of $0.9 \mathrm{p} . \mathrm{u}$ whereas the cageless rotor could not excite beyond $62 \mu \mathrm{F}$. This implies that the cage rotor generator has the ability to excite at capacitance values high enough to circulate rotor current in the machine windings due to the existence of remnant flux, magnetic saturation and rotor geometry. The removal of damper cage of a synchronous reluctance machine allows for more modifications of the rotor geometry which include reduction in the quadrature axis flux path and hence the quadrature axis reactance which ultimately improves the machine performance. This shows that a cage rotor generator can be deployed where higher power is required.
\end{abstract}

Keywords: Reluctance generator, Cage rotor, cage-less rotor, modeling, excitation and synchronous reluctance generator

\section{INTRODUCTION}

Reluctance generator can be described as a special form of salient-pole synchronous machine without rotor excitation. A reluctance machine is an electrical machine in which torque is produced by the tendency of its movable part to move into a position where the reluctance of a magnetic circuit is minimized, i.e. where the inductance of the exciting winding is maximized. Research on threephase reluctance machine started more than half a century ago [1].Reluctance machines have been known as early as induction machines but due to their rather poor performance, they were ignored during the earlier part of the $20^{\text {th }}$ centuryexcept for special applications. Later in the early sixties and seventies, synchronous reluctance machines were extensively investigated as line-start synchronous machines and during the period other rotor designs and applications emerged [2].Since then, many researchers have worked on the analysis of its performance as a motor and compared with that of the induction machine. Mohamadein [3] proposed a model for a self-excited reluctance and this was done to overcome the disadvantages of induction generator. While Brennen [4] carried out a study on the steady-state characteristics of synchronous reluctance generator (with two different rotor structures) and compared with those of the induction generator. Attempts have also been made to derive a model for reluctance generator by treating it as an induction machine [5], thoughin the study, the machine was stripped of its typical saliency features. The modeling and performance of self-excited two-phase reluctance generator using shunt capacitors on the stators for excitation was studied by Obe[6] in which the generator has a balance two phase, two pole stator winding across which RL load can be connected but the work did not explore the rotor performance. However, the research gap exists on the study of a self-excited three-phase synchronous reluctance generator with and without a cage rotor. Three-phase reluctance generator could be applicable where high power is required and therefore a review of its performance with and without a cage rotor is necessary to determine the appropriate areas of its relevance in applications. A review of above previous works provided valuable information on the operating principles and basic equations of synchronous reluctance generator and a basis to compare the performance for a three-phase synchronous reluctance generator with or without a cage rotor. 


\section{RELUCTANCE GENERATOR MODELINGWITH AND WITHOUT A CAGE ROTOR}

The synchronous reluctance machine's stator is identical to that of the induction machine, which ideally has a smoothly rotating magnetic field. The synchronous reluctance rotor, which has salient rotor poles without field coils, is one of the oldest types of electric machines. Even though, there have been numerous studies on the shape of the synchronous reluctance rotor, the main idea is that the magnetic flux produced by the stator has a shortest path through the rotor, which means the smallest magnetic reluctance. The reluctance torque is developed on account of this phenomenon, even without any excitation on the rotor.

Reluctance generator connection for normal operation..

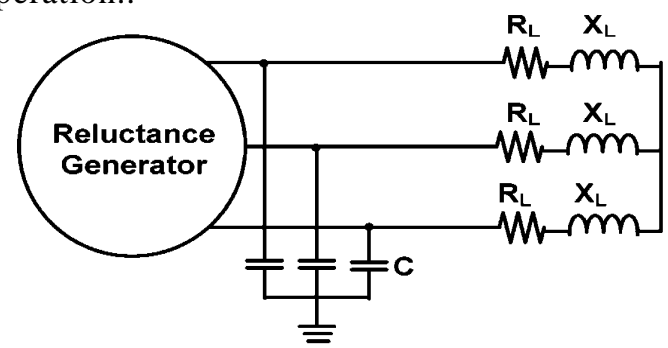

Fig. 1 The connection diagram of the reluctance generator for normal operation

The system comprises a 3-phase reluctance generator with load resistances and inductances connected in parallel to a set of capacitors for excitation.

The analysis of the reluctance machine is based on the following assumptions

1. Field windings are omitted

2. Core-loss resistance $R_{C}$ is assumed to be connected in parallel to the stator winding resistance $R_{S}$

From the machine's (d-q) model,

$\rho \lambda_{q s}=V_{q s}+\left(\frac{R_{s} X R_{c}}{R_{s}+R_{c}}\right) I_{q s}-\omega_{r} \lambda_{d s}$

$\rho \lambda_{d s}=V_{d s}+\left(\frac{R_{s} X R_{c}}{R_{s}+R_{c}}\right) I_{d s}+\omega_{r} \lambda_{q s}$

$\rho \lambda_{q r}^{\prime}=V_{q r}^{\prime}-R_{q r}^{\prime} I_{q r}^{\prime}$

$\rho \lambda_{d r}^{\prime}=V_{d r}^{\prime}-R_{d r}^{\prime} I_{d r}^{\prime}$

The primed quantities are rotor quantities referred to the stator side, while $\boldsymbol{p}$ is the derivative operator, $\boldsymbol{d} / \boldsymbol{d} \boldsymbol{t}$. The flux linkages for the cage and cageless rotor generator are expressed as follows:
Cage rotor generator

$\left[\begin{array}{l}\lambda_{q s} \\ \lambda_{d s} \\ \lambda_{q r} \\ \lambda_{d r}\end{array}\right]=$
$-\left[\begin{array}{cccc}L_{q} & 0 & L_{m q} & 0 \\ 0 & L_{d} & 0 & L_{m d} \\ -L_{m q} & 0 & -L_{q r}+L_{m q} & 0 \\ 0 & -L_{m d} & 0 & L_{l d r}+L_{m d}\end{array}\right]\left[\begin{array}{c}I_{q s} \\ I_{d s} \\ I_{q r} \\ I_{d r}\end{array}\right]$

(5)

Cageless rotorGenerator

$$
\begin{gathered}
\lambda_{q s}=-L_{q} I_{q s} \\
\lambda_{d s}=-L_{d} I_{d s}
\end{gathered}
$$

The mechanical rotation and torque equations of the machine are respectively given by:

$$
\begin{aligned}
& \quad \rho \omega_{r}=\frac{\rho_{r}}{2 J}\left(T_{e}-T_{L}\right) \text { and } T_{e}= \\
& \frac{3}{2} p_{r}\left(\lambda_{d s} I_{q s}-\lambda_{q s} I_{d s}\right)
\end{aligned}
$$

By resolving equations 1 to 5 in rotor reference frame model for the analysis of the connection shown in fig. 1 , the $\mathrm{d}-\mathrm{q}$ rotor reference frame voltage equations for a reluctance machine with and without cage rotor operating as a generator is established by Parks Transformation.

The cage rotor generator equivalent circuit is shown below

$$
\begin{aligned}
& \text { Voltage Equations: } \\
& V_{d s}=\rho \lambda_{d s}-\omega_{r} \lambda_{q s}+\left(\frac{R_{s} R_{c}}{R_{s}+R_{c}}\right) I_{d s} \\
& V_{q s}=\rho \lambda_{q s}+\omega_{r} \lambda_{d s}-\left(\frac{R_{s} R_{c}}{R_{s}+R_{c}}\right) I_{q s}
\end{aligned}
$$

Fig. 2 shows the equivalent circuits of the two-axis model of reluctance synchronous generator having $\mathrm{D}$ and $\mathrm{Q}$ damper windings.

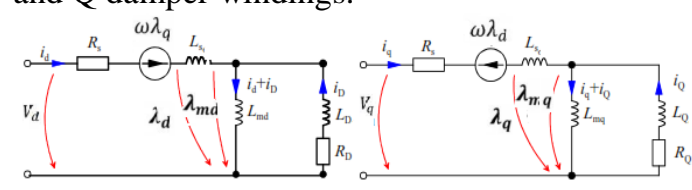

Fig.2 Equivalent circuits according to the twoaxis model for a cage rotor synchronous reluctance machine. The stator voltage and current components are indicated by the subscripts $\mathrm{d}$ and $\mathrm{q}$, damper windings by subscripts $\mathrm{D}$ and $\mathrm{Q} \cdot R_{D}$ and $R_{Q}$ are core-loss resistance

The cageless rotor generator equivalent circuit is shown in fig.3

The stator voltage equations for the cageless rotor machine can be expressed as: 


$$
\begin{array}{r}
\text { Voltage Equations: } \\
V_{d s}=\rho \lambda_{d s}-\omega_{r} \lambda_{q s}+R_{s} I_{d s} \\
V_{q s}=\rho \lambda_{q s}+\omega_{r} \lambda_{d s}+R_{s} I_{q s}
\end{array}
$$
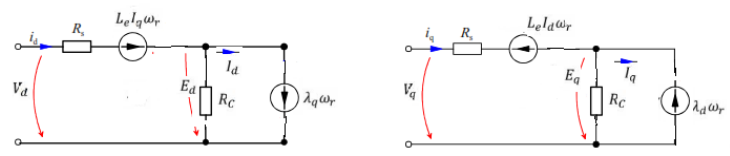

Fig.3Equivalent circuits according to the two-axis model for a cage-less rotor synchronous reluctance machine. The stator voltage and current components are indicated by the subscripts $d$ and q. The two-axis model equivalent circuit for the cage-less rotor synchronous machine in the Fig. 3 is obtained from the corresponding model for a salient polemachine. The components representing the excitation winding of the rotor have been omitted. In modeling of the three-phase synchronous reluctance generator, the synchronous reluctance machine requires a number of machine parameters to be known. These parameters can be obtained through measurements of short-circuit and open-circuit characteristics. This method is based on the determination of the machine parameters from the standard inductances and timeconstants. The model parameters used for this study as expressed in Table 1.0 were obtained from an experiment of a laboratory prototype of a three phase reluctance machine with a stator rated power of 1-kW, 110 Volts, current rated 3.7 Amperes and wound as shown in Fig.1 [7]. The stator resistance per phase was measured by DC test and other parameters as indicated in the Table 1.0. The aim of building and simulating the model was to observe the behavior of the self-excited three phase synchronous reluctance generator.

Direct-axis synchronous inductances are expressed as:

$$
L_{d}, \text { STATOR: } L_{d s}=L_{l s}+L_{m d}
$$

$$
\text { ROTOR: } L_{d r}=L_{m d}+L_{l d r}
$$

Quadrature- axis synchronous inductancesare expressed as:

$$
\begin{aligned}
& L_{q}, \text { ST ATOR: } L_{q s}=L_{l s}+L_{m q} \\
& \text { ROTOR: } L_{q r}=L_{m q}+L_{l q r}
\end{aligned}
$$

The flux linkages, inductances and core loss resistance are also calculated as function of magnetizing flux linkage

$$
\begin{aligned}
& L_{m}=\sqrt{L_{q s}^{2}+L_{d s}^{2}} \\
& \begin{aligned}
L_{m d}=\left(3476.4 L_{m}{ }^{4}-6743.3 L_{m}{ }^{3}+2659.3 L_{m}{ }^{2}\right. \\
\left.\quad-409.67 L_{m}+234.39\right) X 10^{-3} \\
L_{m q}=\left(10219 L_{m}{ }^{4}-12334 L_{m}{ }^{3}+5896.3 L_{m}{ }^{2}\right. \\
\quad-1451.4 L_{m} \\
\quad+183.09) X 10^{-3}(18) \\
L_{L}=\frac{R L}{\omega_{r}} \sqrt{\left(\frac{1}{p . f}\right)^{2}-1}
\end{aligned}
\end{aligned}
$$

where p.f is the power factor

The $\mathrm{d}$ - and q-axis inductances are not constants but depend on the value of the magnetizing flux linkage. The variation of $\mathrm{L}_{\mathbf{q}}$ is actually not very significant but was nonetheless modeled as a variable for accuracy. The core loss resistance $R_{c}$ is calculated by finite element procedure andthe resulting equation for core loss resistance is given as:

$$
\begin{gathered}
R_{c}=-67204 \lambda_{m}{ }^{4}+47606 \lambda_{m}{ }^{3}-9039.2 \lambda_{m}{ }^{2}+ \\
931.35 \lambda+553.42
\end{gathered}
$$

The shunt capacitor equations in the $\mathrm{d}-\mathrm{q}$ rotor reference frame are expressed as:

$$
\begin{aligned}
& \rho V_{q s}=\omega_{r} V_{d s}+\frac{I_{q s}-I_{q L}}{C} \\
& \rho V_{d s}=\omega_{r} V_{q s}+\frac{I_{d s}-I_{d L}}{C}
\end{aligned}
$$

The following general series R-L load model is adopted:

$\rho I_{q L}=\frac{V_{q s}-R_{L} I_{q L}-\omega_{r} L_{L} I_{d L}}{L_{L}}$

$\rho I_{d L}=\frac{V_{d s}-R_{L} I_{d L}+\omega_{r} L_{L} I_{q L}}{L_{L}}$

The expression for other parameters like phase voltage, current and power are stated below:

$V_{v}=V_{d} \cos \theta+V_{q} \sin \theta$

$$
V_{V V}=\sqrt{V_{d s}^{2}+V_{q s}^{2}}
$$

$$
I_{a}=I_{q} \cos \theta+I_{d} \sin \theta
$$


$I_{a L}=I_{q L} \cos \theta+I_{d L} \sin \theta$

$$
P_{o}=3 I L^{2} R L
$$

$I_{L}=\frac{\sqrt{I_{q L}^{2}+I_{d L}^{2}}}{\sqrt{2}}$

Table 1.0 Synchronous reluctance generator model parameters

\begin{tabular}{|l|l|l|l|l|l|l|}
\hline Machine Rating & $\mathrm{R}_{\mathbf{s}}$ & $\mathrm{R}_{\mathbf{q r}}$ & $\mathrm{R}_{\mathbf{d r}}$ & $\mathrm{L}_{\mathbf{q r}}$ & $\mathrm{L}_{\mathbf{d r}}$ & $\mathrm{L}_{\mathbf{l s}}$ \\
\hline Unit & $\operatorname{Ohms}(\Omega)$ & $\operatorname{Ohms}(\Omega)$ & $\operatorname{Ohms}(\Omega)$ & Henry $(\mathrm{H})$ & Henry(H) & Henry $(\mathrm{H})$ \\
\hline Value & 0.7 & 1.4 & 1.1 & 0.0024 & 0.002 & 0.002 \\
\hline
\end{tabular}

III. Simulation in MATLAB/SIMULINK

Fig. 4 Shows Simulink Model of Three-phase Reluctance Generator

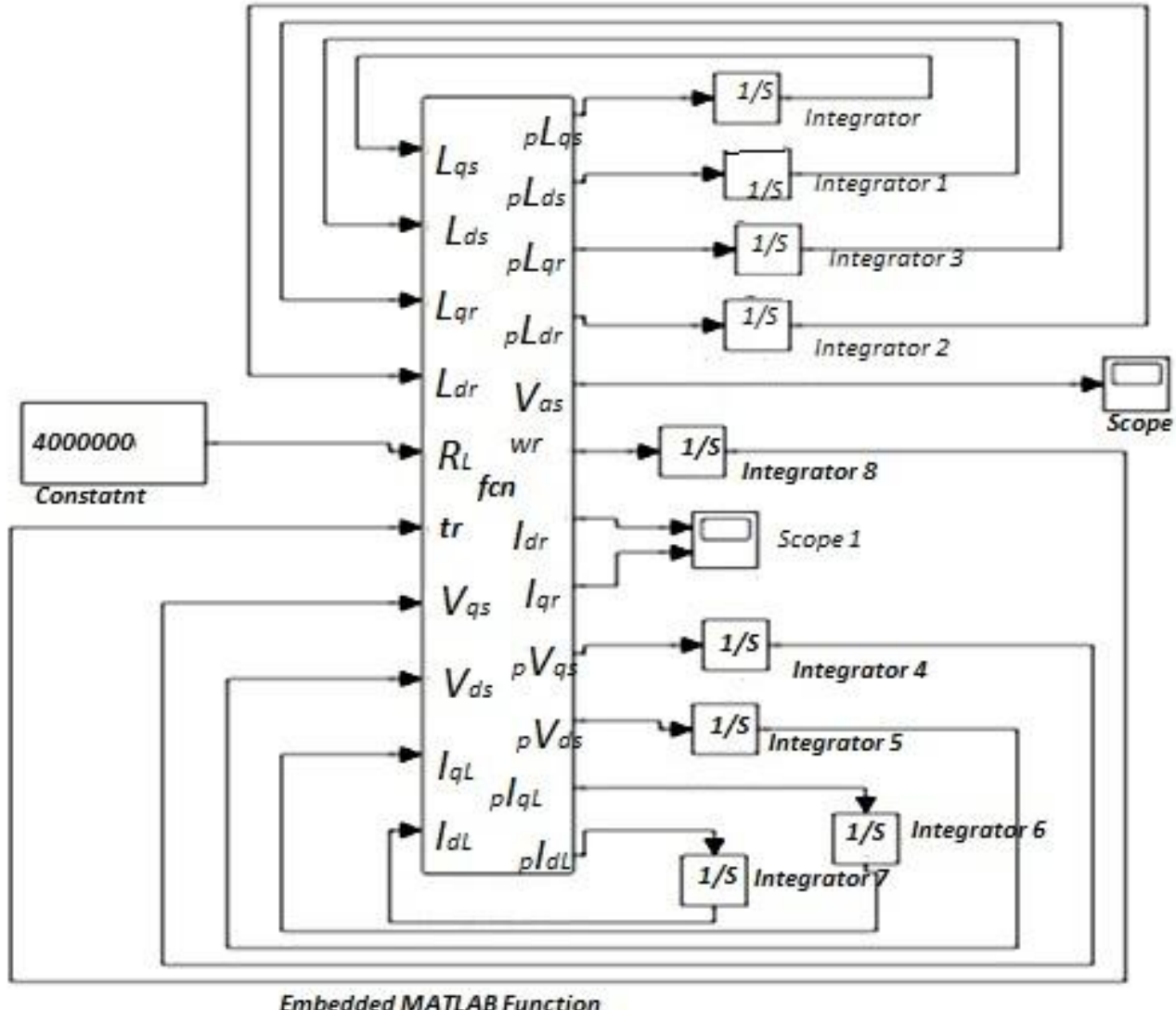

Figure 4 Simulink Model of Three-phase Reluctance Generator

The simulation was carried out using MATLAB/SIMULINK software where the Equations 1 to 30 and parameters in Table 1.0 were implemented in Embedded MATLAB function in SIMULINK environment. The results obtained were compiled in a work space and appropriate axes used to produce the results.

\section{RESULTS AND DISCUSSION}

The generator parameters shown in Table 1.0 were used in the simulation which was carried out under steady state condition, variant excitations and load conditions; while figs 5 to 21 show the results. 


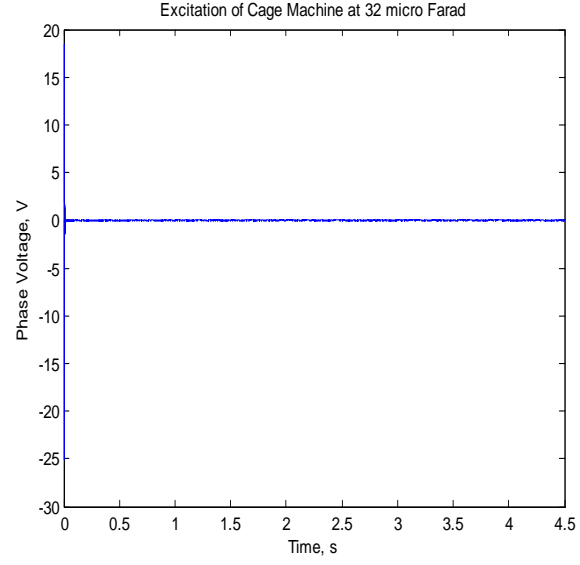

Fig. 5 Voltage build-up at $\mathrm{C}=32 \mu \mathrm{F}$ for a generator with a cage

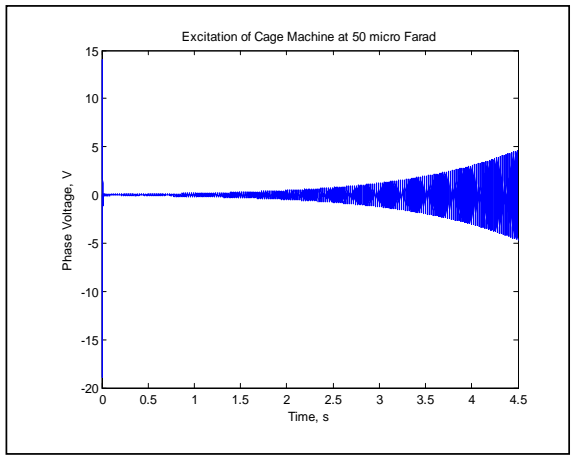

Fig7: Voltage build-up at $\mathrm{C}=50 \mu \mathrm{F}$ generatorcageless rotor generator

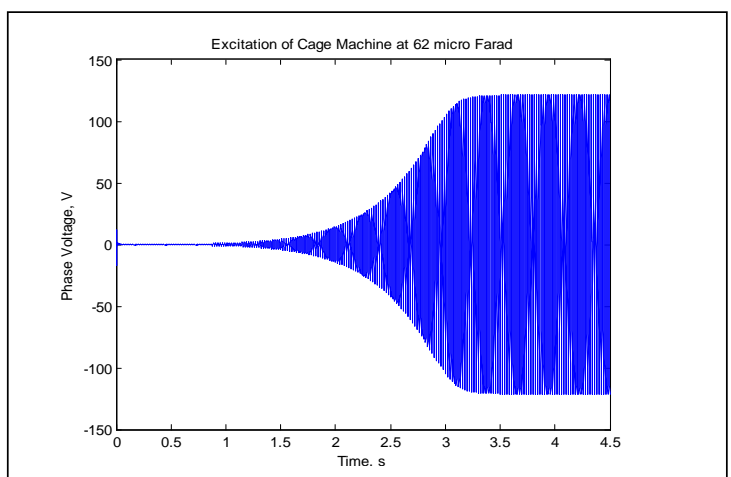

Fig 9: Voltage build-up at $\mathrm{C}=62 \mu \mathrm{F}$ for a cageless rotor generator

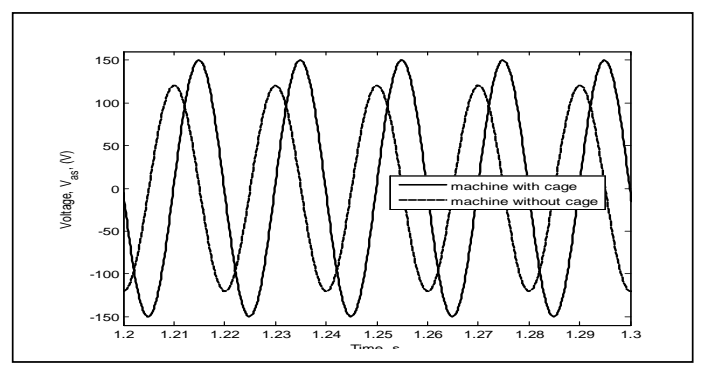

Fig 11: Voltage build-up at $\mathrm{C}=62 \mu \mathrm{F}$ for both cage and cageless rotor generator

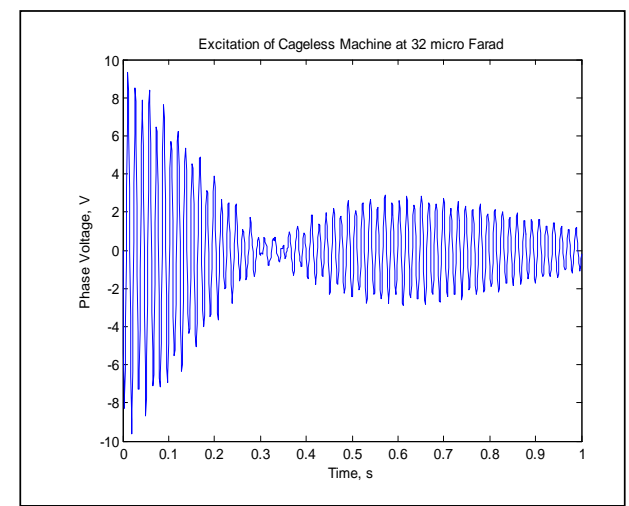

Fig. 6 Voltage build-up at $\mathrm{C}=32 \mu \mathrm{F}$ for a generator with a cage

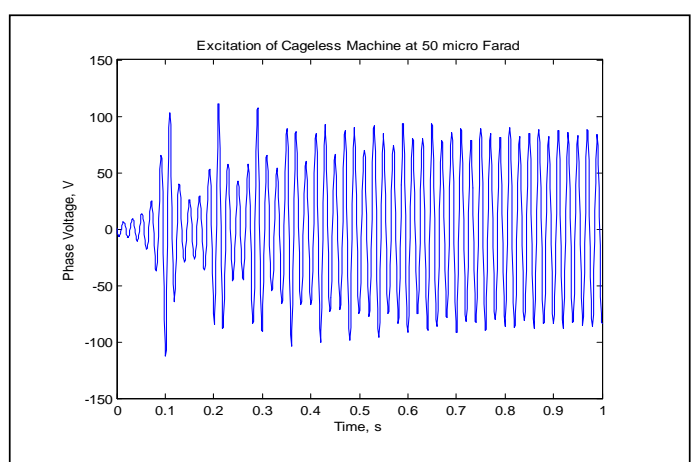

Fig 8: Voltage build up at $\mathrm{C}=50 \mu \mathrm{F}$ for a for a cage rotor

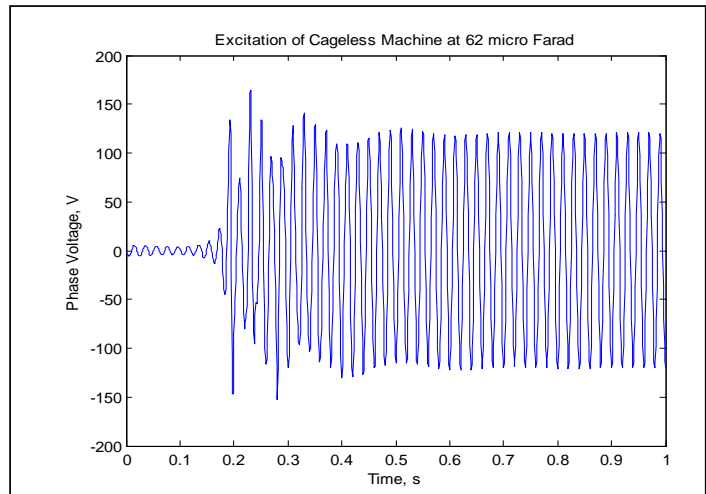

Fig 10: Voltage build-up at $\mathrm{C}=62 \mu \mathrm{F}$ for a cage rotor generator

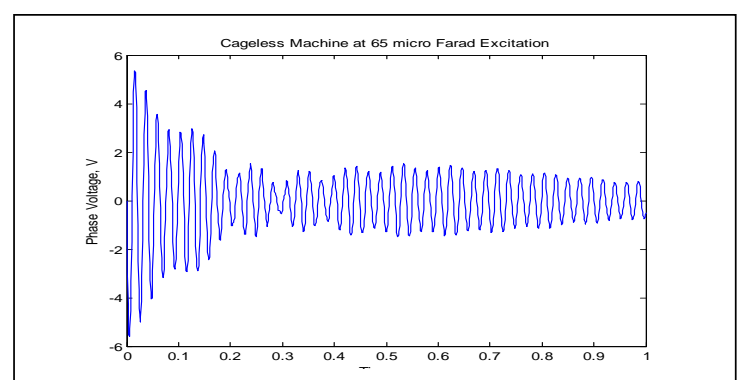

Fig 12: Voltage build-up at $\mathrm{C}=65 \mu \mathrm{F}$ for a cageless rotor generator 


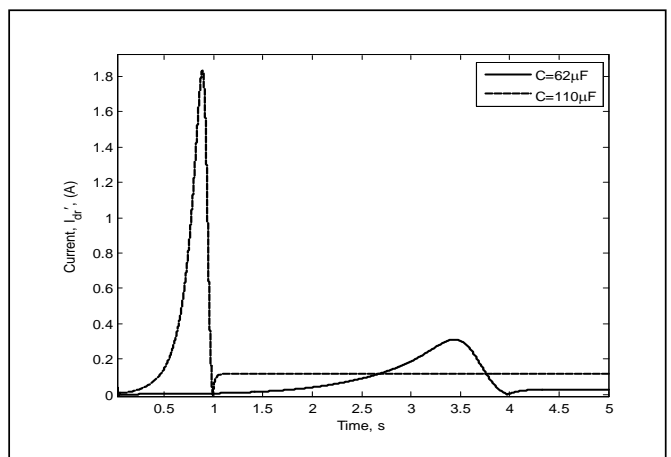

Fig. 13: Simulated cage rotor current in

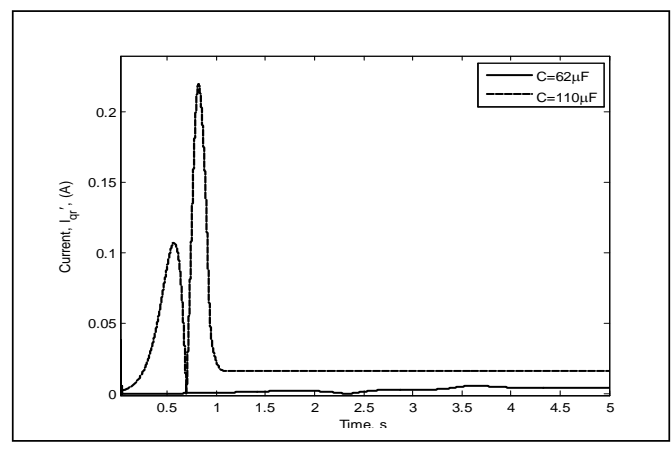

Fig. 14: Simulated cage rotor current in direct: $d$-axis $\left(I_{\mathbf{d r}}\right)$ during excitationquadrature: $q$-axis $\left(\mathrm{I}_{\mathbf{q r}}\right)$ during excitation

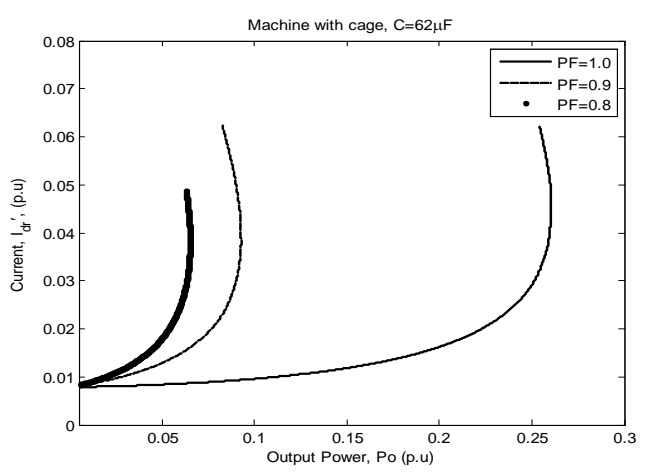

Fig.15: D-axis rotor current (p.u) versus Output

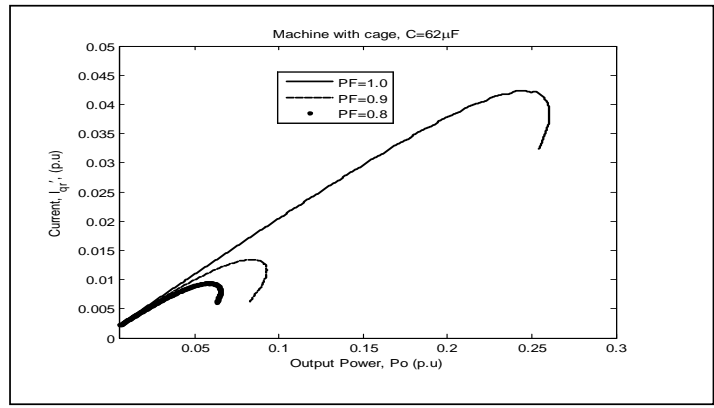

Fig.16: Q-axis rotor current (p.u) versus Output power (p.u) at $\mathrm{C}=62 \mu \mathrm{F}$ for cage machinepower (p.u)at $\mathrm{C}=62 \mu \mathrm{F}$ for cage machine

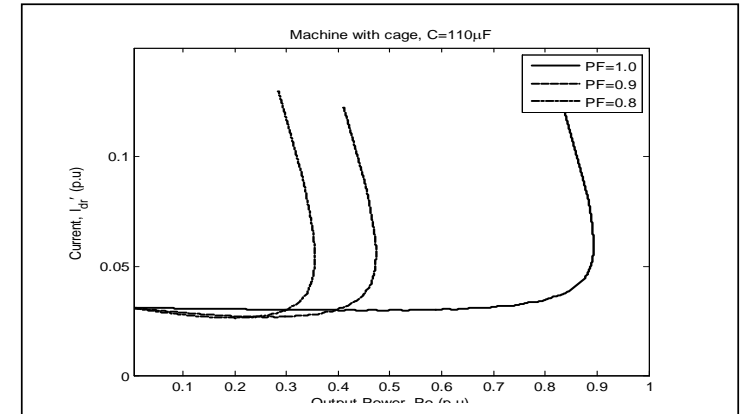

Fig.17: D-axis rotor current (p.u) versus Output power (p.u) at $\mathrm{C}=110 \mu \mathrm{F}$ for cage machine power (p.u) at $\mathrm{C}=11 \mathrm{c}$

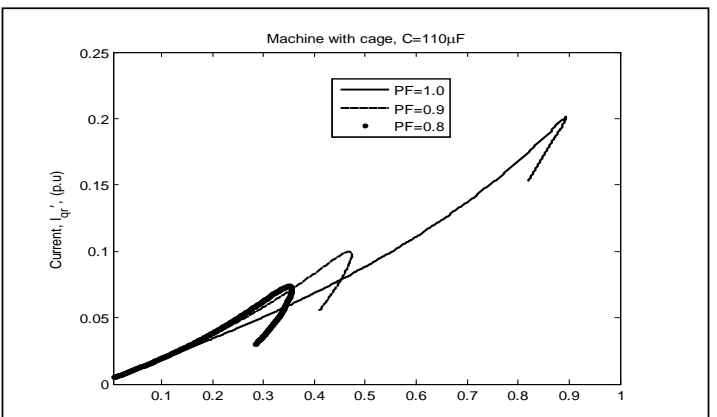

Fig.18: Q-axis rotor current (p.u) versus Output $10 \mu \mathrm{F}$ for cage machine

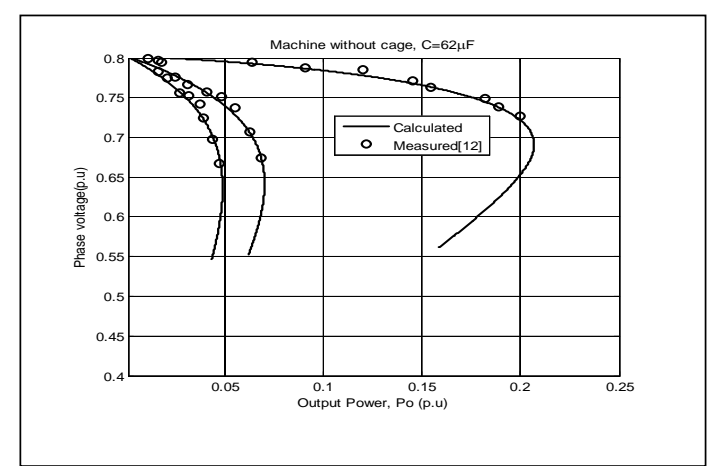

Fig. 19: Phase Voltage (p.u) versus Output Fig. 20: 
Phase Voltage (p.u) versus Output

power (p.u) for cage rotor machine at $\mathrm{C}=$

$62 \mu$ Fpower (p.u) for cageless rotor at $\mathrm{C}=62 \mathrm{Mf}$

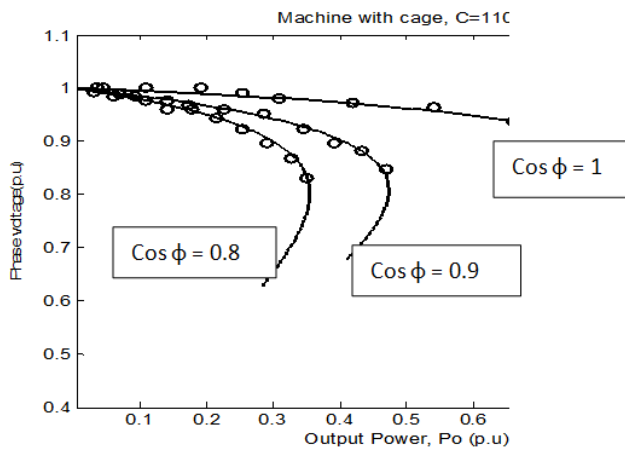

Fig. 21: Phase voltage (p.u) versus Output power (p.u) for cage rotor at $\mathrm{C}=110 \mu \mathrm{F}$

(i)

\section{DISCUSSION}

\section{Varying Excitation}

For comparative study, both cage and cage-less machines were subjected to varying excitations of $32 \mu \mathrm{F}, 50 \mu \mathrm{F}$ and $62 \mu \mathrm{F}$. Figs. 5 to 10show the effects of varying excitation at $32 \mu \mathrm{F}$, $50 \mu \mathrm{F}$ and $62 \mu \mathrm{F}$ for a cage rotor machine and same excitation for cageless rotor machine. Excitation at $62 \mu \mathrm{F}$ which basically indicates the highest value the cageless machine under shunt excitation can accommodate as shown in Fig. 10 for the machine under study. It was further realized that the cageless machine could not excite further beyond $62 \mu \mathrm{F}$ as shown in Fig. 12.For excitation with the capacitance of $32 \mu \mathrm{F}$, the cage rotor machine showed no response, while cageless responded slightly with some degree of instability as shown in Fig. 5 and 6 respectively. Also, deploying the capacitance values of $50 \mu \mathrm{F}$ and $62 \mu \mathrm{F}$ respectively,forcaged rotormachine, it took some time for excitation to take place but remained stable over a period of time, when compared to the cageless which was fasterbut not as stable as in caged machine. At $62 \mu \mathrm{F}$ capacitance, the excitation in caged rotor produced higher phase voltage as compared to cageless machine over a longer period of time as shown in Fig. 11.Therefore, Cage rotor has the ability to produce more power; whereas the cageless rotor machine could not excite beyond a capacitance value of $62 \mu \mathrm{F}$ and therefore is limited in power capability when compared to a cage rotor machine.

\section{(ii) Steady State Condition}

Figs.13 and 14. shows the rotor current in the daxis and $\mathrm{q}$-axis during an excitation at $\mathrm{C}=62 \mu \mathrm{F}$ and $110 \mu \mathrm{F}$ respectively for a cage rotor machine; while the cageless rotor machine under study could not self-excite beyond a capacitance value of $62 \mu \mathrm{F}$ i.e $(\mathrm{C}>62 \mu \mathrm{F})$ as shown in Figure 12. It was observed that as the stator voltage is being built-up, the rotor current rises sharply, but as soon as the voltage is settled to full steady-state value, it settles to zero. This is the situation when caged rotor machine is excited at $\mathrm{C}=62 \mu \mathrm{F}$ and $\mathrm{C}=110 \mu \mathrm{F}$ at a constant speed of 1500rpm. This further confirms that the cage rotor machine under study is stable at steady state. The thick line is for excitation at $62 \mu \mathrm{F}$ and dashed line is for excitation at $110 \mu \mathrm{F}$ as shown in Figures 13 and 14. An indication of increased flux path in d-axis and a reduced flux path in qaxis; hence the q-axis reactance which eventually improves the machine performance due to its high saliency ratio.

\section{(iii) Variant Load}

From Figure 15 to 16 , it can be deduced that even at low capacitance value of $62 \mu \mathrm{F}$, the cage machine can deliver higher output power at variant power factors of $0.8,0.9$ and 1.0. The rotor current at higher capacitance of $\mathrm{C}=110 \mu \mathrm{F}$ yielded an increased power output compared to capacitance value of $\mathrm{C}=62 \mu \mathrm{F}$ as seen in Figure 17 and 18. Also, the phase voltage at $\mathrm{C}=62 \mu \mathrm{F}$ for both cage and cagelessat variant power factors resulted in higher output power in caged machine than in cageless machine with cage rotor machine producing about 0.27 p.u while cageless produced 0.20 p.u at p.f of 1.0 as shown in Fig. 19 and 20 respectively.On further excitation of cage rotor machine ata higher capacitance of $\mathrm{C}=110 \mu \mathrm{F}$ as shown in Fig. 21, the power output yielded about 0.9 p.u at power factor of 1.0. This further confirms that a cage rotor machine has a better power output than a cageless machine.

Therefore, for the cage rotor machine under study, increase in capacitance value at varying power factortranslates to increase in output power.

\section{CONCLUSION}

From the research, the following can be deduced:

(i) Excitation at capacitance value of $(\mathrm{C}=62 \mu \mathrm{F})$, cage generator under study yielded a maximum power of 0.26 p.u, while cage-less generator gave the output power of $0.2 \mathrm{p} . \mathrm{u}$

(ii) For cage generator at excitation of $(\mathrm{C}=110 \mu \mathrm{F})$, the maximum power that can be obtained with resistive loading is about 0.9 p.u, while the cage-less cannot excite beyond $\mathrm{C}>62 \mu \mathrm{F}$

(iii) A cage rotor generator exhibits a better ability to preserve the voltage wave shape with varying load than the generator without a cage rotor. This is made possible by the ability of the cage rotor generator to support direct current in the d-axis and making it to act as a field winding during transient disturbance. 
(iv) Also, cage rotor reluctance generator produces more power at higher capacitance value than the cage-less rotor which produces lesser power. This is due to its ability to excite at capacitance values high enough to circulate the rotor current in the machine windings.

\section{REFERENCES}

[1]. Nagrial, M. H \&Rahman, M. A "Operation and Characteristics of self-excited reluctance generator" IEEE Proceedings 1988, (1) pp55-58

[2]. Lawrenson, P.J and Gupta, S.K. Developments in the Performance and Theory of Segmental-rotor Reluctance Machines. Proc. IEE, 114(5), pp. 645 -653, 1967.

[3]. Mohamedian. A, Rahim .Y and Al-Khalaf .A, "Steady State Performance of self excited reluctance generator". IEEE Proceedings 1990, 137, (5) pp29.

[4]. Brennen, M.B. \&Abbandanti, A“Static exciters for induction generators", IEEE Trans. Ind. Applic. 13 (5) (1977) 422-428.

[5]. Watson, D. B and Arrilaga, J "Controllable dc-power supply from wind driven selfexcited induction machines" IEEE Trans. Ind. Applic 1979,Volume 126, Issue 12 pp 1245

[6]. Obe, E.S and Onwuka, I.K "Modeling and performance of self-excited two-phase reluctance generator" Nigerian Journal of Technology. Vol. 30, No. 2, June 2011.

[7]. Obe, E. S andAnih, L "Influence of Rotor cage on the performance of a synchronous reluctance generator" Electric Power Components and Systems Publications, 38(8), pp. 960-97, 2011. 